\title{
Article
}

\section{Population genetics data for 21 autosomal STR loci for United Arab Emirates (UAE) population using next generation multiplex STR kit}

\author{
Ali Alhmoudi, Osamah, Jones, Rebecca J, Tay, Guan K, Alsafar, \\ Habiba and Hadi, Ss \\ Available at http://clok.uclan.ac.uk/13862/ \\ Ali Alhmoudi, Osamah, Jones, Rebecca J, Tay, Guan K, Alsafar, Habiba and \\ Hadi, Ss ORCID: 0000-0002-2994-3083 (2015) Population genetics data for 21 \\ autosomal STR loci for United Arab Emirates (UAE) population using next \\ generation multiplex STR kit. Forensic Science International: Genetics, 19 . \\ pp. 190-191. ISSN 18724973
}

It is advisable to refer to the publisher's version if you intend to cite from the work. http://dx.doi.org/10.1016/j.fsigen.2015.07.009

For more information about UCLan's research in this area go to http://www.uclan.ac.uk/researchgroups/ and search for <name of research Group>.

For information about Research generally at UCLan please go to http://www.uclan.ac.uk/research/

All outputs in CLoK are protected by Intellectual Property Rights law, including Copyright law. Copyright, IPR and Moral Rights for the works on this site are retained by the individual authors and/or other copyright owners. Terms and conditions for use of this material are defined in the policies page. 


\section{Forensic Population Genetics-Letter to Editor}

Dear JM,

DNA samples were analysed from 519 healthy, unrelated and consenting individuals who reside in the United Arab Emirates (UAE) and were randomly chosen for this study. The UAE is one of the middle-eastern countries located on the Arabian Gulf. It shares a border with Iran, Saudi Arabia and Oman. The UAE was founded in 1971, and consists of seven Emirates: Abu Dhabi, Dubai, Sharjah, Ajman, Ra's Al-Khaymah, Al-Fujairah and Umm AlQuwain [1]. According to the National Bureau of Statistics, (2012), the total UAE population was reported to be around 8.26 million in 2010 [2]. The statistics showed that some $11.5 \%$ of the total population comprised of native Arabs, with majority of the population being of Indian and Pakistani ethnicities. In the early part of the twentieth century, the different Arabic tribes migrated in different directions in search of suitable locations to colonize. Some moved into coastal regions, while others inhabited the desert. Despite the modernization throughout the union, the basic family structure and pattern of native UAE Arab population has remained unchanged. Culturally, the preference for consanguineous marriages remains embedded in the society [3]. However, as the awareness of the social and medical impact of consanguinity increases and with diversification, non-consanguineous marriages appear to be on the increase, which has possibly resulted in greater genetic diversity throughout the population $[4,5]$. The increase in genetic diversity in the population is of interest to assess whether STR markers can be used for forensic and paternity purposes. This study expands on previous publications with regards to the analysis of UAE populations with the amplification of additional STR markers and a larger population sample size [6].

The DNA samples analysed in the current study were obtained from indigenous UAE nationals residing in Abu Dhabi, UAE in accordance with approval from the Ethics committee of the Ministry of Health of the United Arab Emirates (2011). Informed consent was received from every volunteer during this collection process and de-identified data is presented. This study was also approved by the Ethics committee of the University of Central Lancashire (2014) as it was carried out as part of Masters Project in DNA profiling. 
The DNA samples provided for this study were collected and extracted using the Genotek's Oragene-DNA kit (Genotek, Ottawa, Canada) in accordance with manufacturer's guidelines. The quantities of extracted DNA samples were determined using a NanoDrop spectrophotometer (Thermo Scientific, Wilmington DE, USA).

Using half volume $(7.5 \mu \mathrm{l})$ reactions, samples were amplified using the GlobalFiler ${ }^{\circledR}$ PCR amplification kit (Life Technologies, Foster City CA, USA) and alleles were called using the allelic ladder provided by the manufacturer. The PCR was performed in the GeneAmp® PCR System 9700 (Life Technologies). The GlobalFiler ${ }^{\circledR}$ PCR amplification kit (Life Technologies) amplifies 21 autosomal STR loci, a Y-STR locus DYS 391, a Yindel marker and Amelogenin. The 21 autosomal STR loci within this amplification kit were of interest for the purposes of this study. The 21 autosomal loci amplified and focused on within this study were D3S1358, vWA, D16S539, CSF1PO, TPOX, D8S1179, D21S11, D18S51, D2S441, D19S433, TH01, FGA, D22S1045, D5S818, D13S317, D7S820, SE33, D10S1248, D1S1656, D12S391, D2S1338.

The PCR products were analysed using an 8 capillary ABI 3500 DNA Genetic Analyser with POP-4 ${ }^{\mathrm{TM}}$ polymer (Life Technologies). GeneMapper ${ }^{\circledR}$ Software version 4.0 (Life Technologies) was then used for analysis. LIZ-600 was used as internal Standard (Life Technologies).

The alleles from all loci reported here were designated using the allelic ladder supplied by the manufacturer, according to the published nomenclatures and the guidelines of the International Society for Forensic Genetics (ISFG) for performing STR analyses [7].

The STR allele frequencies along with the parameters of population genetics: observed and expected heterozygosity (Ho and He, respectively), power of discrimination (PD), probability of exclusion (PE), and polymorphic information content (PIC) were estimated using PowerStats version 1.2 (Promega, Madison, USA) (Supplementary Table 1). Version 3.11 of the Arlequin software was used to perform an exact test to investigate any departures from the Hardy-Weinberg equilibrium (HWE) [8]. The theoretical profile frequency range was estimated signifying the rarest and most common heterozygous genotypes. Furthermore, the number of possible genotypes was also calculated (Supplementary Table 2). 
The data generated from this study was compared to 5 published population data sets for available loci [9]. Exact test comparisons were made between this current study of the UAE population in this study and data from Kuwaiti, India, Saudi Arabia, Egypt, and Iran.

Data is available upon request from shadi@uclan.ac.uk

Through the analysis of allele frequency data, allele 8 of TPOX was found to exhibit the highest allele frequency with $49.4 \%$ in the total samples analysed for the population. During analysis, two off ladder allelic variants were observed at locus SE33. These variants were allele 7.3 (within 3 samples) and allele 17.3 (within 1 sample). Both of these variants have been previously reported on STRBase [9]. A tri-allelic pattern (allele 6, 8, 10) was observed for TPOX during analysis which has also been previously reported on STRBase [10]. The SE33 locus showed the largest number of different alleles (50 alleles) and D13S1358, D16S539 and CSF1PO loci showed the smallest number of different alleles (8 alleles). The heterozygosity $(\mathrm{Ho})$ of the 21 autosomal STR loci ranged from $65 \%$ (TPOX) to 92\% (SE33). The power of discrimination values (PD) for all tested loci was above 85\%; the highest observed at SE33 with 99.3\% and the least at TPOX with $85 \%$. The combined probability of exclusion (CPE), power of discrimination (CPD) and matching probability (CMP) for all 21 STR loci were 0.999999999999999999999999994, $99.999 \times 10^{-2}$ and $6.2468 \times 10^{-27}$ respectively. When HWE was tested, there was no statistical significance observed for 19 out of 21 autosomal STR loci. Bonferroni correction was applied to the two loci (D8S1179 and D22S1045) that showed deviation from HWE after which no significant departure was observed. The data for the most common STR profile from the UAE population (based on this dataset) showed that even using a very conservative value of 0.05 for Fst leads to a discrimination power in the order of $10^{15}$, which translates into a value which is much higher than 1 in a billion. These estimates indicate that UAE might like to adopt a match probability estimates to be reported by the laboratories (in case of a full match) based on statistics generated using its own population allele frequency data. Further work is indicated in this area in order to develop guidelines for forensic DNA laboratories in UAE.

Some significant differences were identified between the obtained UAE population data and the other published data. The populations from Iran and Saudi Arabia showed 
significant differences at fewer loci when compared with populations from Kuwait, Egypt and India $(P>0.05)$. This is also supported by low FST value for the Iranian and Saudi Arabian populations. These results support the development of population or location specific databases even when considering populations that are geographically close such as within the Middle East (Supplementary Table 3).

This current dataset establishes the characteristics of the 21 STR loci panel for the identification of individuals, in paternity testing and for crime scene analysis in the UAE.

This manuscript of population data follows the journal guidelines for publication of data described [11, 12 and 13].

\section{Acknowledgments}

We acknowledge Khalifa University, Abu Dhabi for hosting the project and the Abu Dhabi Police General Head Quarter for sponsoring the studies of AAO through a scholarship.

\section{Appendix A. Supplementary data}

PublicationlSupplementary Table 1.xIsx

PublicationISupplementary Table 2.xlsx

\section{PublicationlSupplementary Table 3.xIsx}

\section{References}

[1] S.B. Miles. The countries and tribes of the Persian Gulf, London, Harrison and Sons (1919).

[2] National Bureau of Statistics. Demographic and Social Statistics. Internet. 19-12012. 19-12-2011.

[3] G.O. Tadmouri, P. Nair, T. Obeid, M.T. Al Ali, N. Al Khaja, H.A. Hamamy, Consanguinity and reproductive health among Arabs, Reprod Health. 6 (2009) 17. [4] I. Abed, P. Hellyer. United Arab Emirates, a New Perspective, London, Trident Press (2001).

[5] T. Mohammad, Y. Xue, M. Evison, \& C. Tyler-Smith, Genetic structure of nomadic Bedouin from Kuwait, Heredity. 103 (5) (2009) 425-433. 
[6] R. Garcia-Bertrand, T.M Simms, A.M Cadenas, R.J Herrera, United Arab Emirates: Phylogenetic relationships and ancestral population s, Gene. 533 (2014) 411-419.

[7] P.M. Schneider, Scientific standards for studies in forensic genetics, Forensic Sci. Int. 165 (2007) 238-243.

[8] L. Excoffier, G. Laval, \& S. Scnheider, Arlequin ver. 3.0: An integrated software package for population genetics data analysis, Evol Bioinform. 1 (2005) 47-50.

[9] M. Al-Enizi, J. Ge, S. Ismael, H. Al-Enezi, A. Al-Awadhi, W. Al-Duaij, B. Al-Saleh, Z. Ghulloom, B. Budowle, Population genetic analyses of 15 STR loci from seven forensically-relevant populations residing in the state of Kuwait, Forensic Sci Int- Gen. 7(4) (2013) e106-e107.

[10] C.M. Ruitberg, D.J. Reeder, J.M. Butler, STRBase: A short tandem repeat DNA database for the human identity testing community, Nucl. Acids Res. 29 (1) (2001) 320322.

[11] A. Carracedo, J.M Butler, L. Gusmão, A. Linacre, W. Parson, L. Roewer, P.M, Schneider, Update of the guidelines for the publication of genetic population data, Forensic Sci. Int. Gen. 10( 2014) A1 - A2.

[12] A. Carracedo, J.M Butler, L. Gusmão, A. Linacre, W. Parson, L. Roewer, P.M, Schneider, New guidelines for the publication of genetic population data, Forensic Sci. Int. Gen. 7 (2013) 217-220.

[13] P. Lincoln, A. Carracedo, Publication of population data of human polymorphisms, Forensic Sci Int. 110 (2000) 3-5. 